\title{
Differentiation of Spinal Damage through Compression Mechanism
}

Jerzy Kiwerski, MD

Rehabilitation Clinic of the Medical Academy in Warsaw, Konstancin, Poland.

\section{Summary}

In the years 1965 to 1986, 986 patients with spine fractures caused by compression were treated at the Rehabilitation Clinic. This communication presents an analysis of those patients, taking into account the significant differences between typical compression fractures and explosion fractures, the latter are, as a rule, complicated by considerable or complete spinal cord damage. The author has pointed to the differences in the indication for surgery, different prognosis and significantly different results of treatment. The author is of the opinion that, due to those differences, the two kinds of spinal fractures should be considered separately with regard to the analysis of the mechanism of injury, the prognosis and the assessment of the results of treatment.

Key words: Compression spinal injury; Explosion spinal fractures; Spinal cord injury; Results of treatment.

Compression fractures of the spine are generally regarded as having the best prognosis on account of the relatively small danger of primary or secondary injury to the spinal cord (e.g. during transport) (Bedbrook, 1979; Decoulx, 1981; Denis, 1983; Holdsworth, 1970). This is due to the stable nature of the injury. Buhr points out the high incidence of this kind of injury in elderly persons, usually following minor spinal injuries. Our experience (Kiwerski and Kulikowski, 1986), however, shows that the compression group is not homogenous and comprises not only typical compression fractures where such patients indeed have a good prognosis, but also the so-called crush or explosion fractures involving serious damage to the nervous system (Fig. 1). McAfee (1982), presents similar observations regarding explosion fractures as unstable spinal injuries. This paper aims to present the differences between those two types of 'compression' fractures based on our clinical material. 

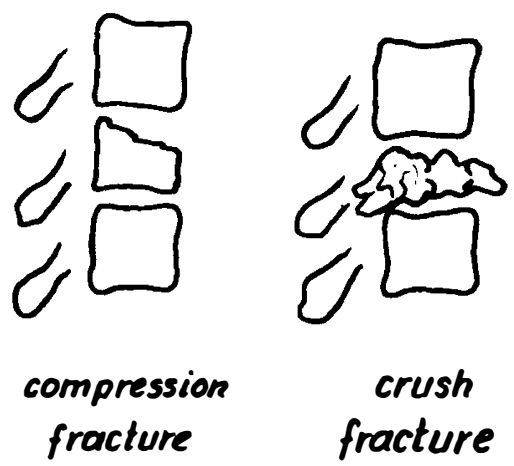

fracture

Figure 1 Line-drawing in lateral projection showing the two main types of compression fractures.

\section{Clinical material}

Within the years 1965 to 1986 there were 986 patients with spinal injury through compression mechanism treated at the Rehabilitation Institute, Konstancin. The compression group made up $35 \%$ of all our spinal patients treated over that time.

Table I presents the level of spinal injury, the age of the patients and the types of fracture. The type of fracture was assessed on the basis of the spinal X-ray. Compression fractures are usually considered stable because the posterior bony elements, the laminae, facets, pedicles and posterior part of the body are intact (Fig. 2). If the force is sufficiently great to produce an explosion (bursting) fracture, a posterior fragment of the body may also be forced into the vertebral canal (Fig. 3). The most severe injuries to the spinal cord occur with this type of injury, and the neurological deficit is usually sudden, and conservative reduction of the fracture is very difficult. In the analysed group (Table I) there were 620 compression (63\%) and $366(37 \%)$ crush fractures. The injuries most frequently involved the lower cervical spine ( $347=35 \%$ of total 986$)$ and the thoraco-lumbar spine $(311=31.5 \%$ of 986$)$. Crush fractures were most frequent in the lower cervical spine, making up $56 \%$ of 366 , while compression fractures prevailed in injuries to other segments of the spine, particularly its lower regions (T12 and below). Crush fractures were seldom recorded in the upper cervical spine. The analysis of the age of the patients shows that crush fractures were more frequent in

Table I Level of spinal injury and age of patients

\begin{tabular}{|c|c|c|c|c|c|c|c|c|c|}
\hline \multirow{2}{*}{$\begin{array}{l}\text { Level } \\
\text { of spinal } \\
\text { injury }\end{array}$} & \multicolumn{3}{|c|}{$\begin{array}{c}\text { Compression } \\
\text { age (years) }\end{array}$} & \multicolumn{5}{|c|}{$\begin{array}{c}\text { Crush } \\
\text { age (years) }\end{array}$} & \multirow[b]{2}{*}{ Total } \\
\hline & to 35 & $36-50$ & over 50 & Subtotal & to 35 & $36-50$ & over 50 & Subtotal & \\
\hline $\mathrm{C}_{1}-\mathrm{C}_{4}$ & 14 & 6 & 6 & $26 \quad(4 \cdot 2 \%)$ & 7 & 4 & 1 & $12(3 \cdot 3 \%)$ & 38 \\
\hline $\mathrm{C}_{5}-\mathrm{C}_{7}$ & 89 & 27 & 38 & $154(24 \cdot 8 \%)$ & 163 & 25 & 5 & $193(52 \cdot 7 \%)$ & 347 \\
\hline $\mathrm{D}_{1}-\mathrm{D}_{6}$ & 8 & 10 & 14 & $32(5 \cdot 2 \%)$ & 17 & 6 & 3 & $26(7 \cdot 1 \%)$ & 58 \\
\hline $\mathrm{D}_{T}-\mathrm{D}_{11}$ & 19 & 14 & 27 & $60(9 \cdot 7 \%)$ & 30 & 14 & 5 & $49(13 \cdot 4 \%)$ & 109 \\
\hline $\mathrm{D}_{12}-\mathrm{L}_{1}$ & 62 & 64 & 119 & $245(39 \cdot 5 \%)$ & 47 & 16 & 3 & $66(18 \cdot 0 \%)$ & 311 \\
\hline $\mathrm{L}_{2}$ and below & 28 & 30 & 45 & $103(16 \cdot 6 \%)$ & 14 & 6 & - & $20(5 \cdot 5 \%)$ & 123 \\
\hline Total & $\begin{array}{l}220 \\
(36 \%)\end{array}$ & $\begin{array}{l}151 \\
(24 \%)\end{array}$ & $\begin{array}{l}249 \\
(40 \%)\end{array}$ & $\begin{array}{l}620 \\
(100 \%)\end{array}$ & $\begin{array}{l}278 \\
(76 \%)\end{array}$ & $\begin{array}{l}71 \\
(19 \%)\end{array}$ & $\begin{array}{l}17 \\
(5 \%)\end{array}$ & $\begin{array}{l}366 \\
(100 \%)\end{array}$ & 986 \\
\hline
\end{tabular}


young people (see Table I), whereas older people are more likely to sustain typical compression fractures. Crush fractures were noted in $56 \%$ of 498 patients up to 35 years-of-age and in $32 \%$ of 222 patients of 36 to 50 years-of-age. Compression fractures were recorded in $94 \%$ of 266 patients over 50 .

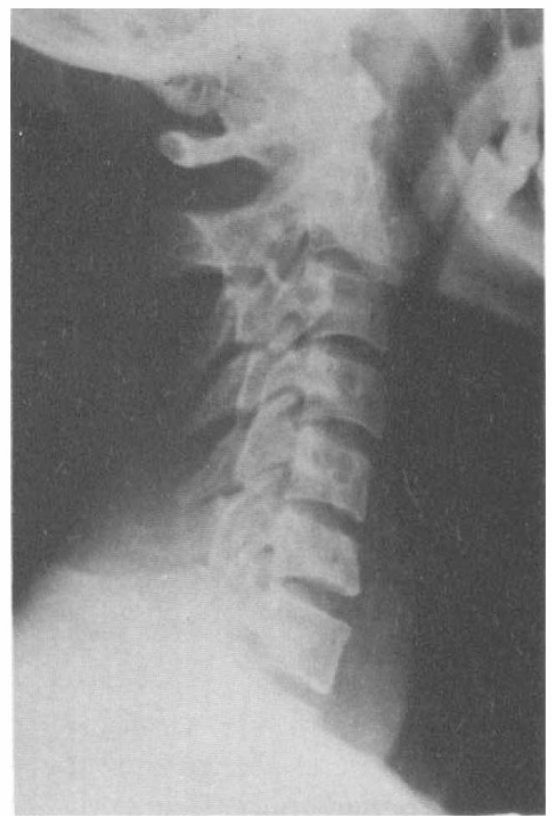

Figure 2 A lateral view of the cervical spine showing compression of a vertebral body.

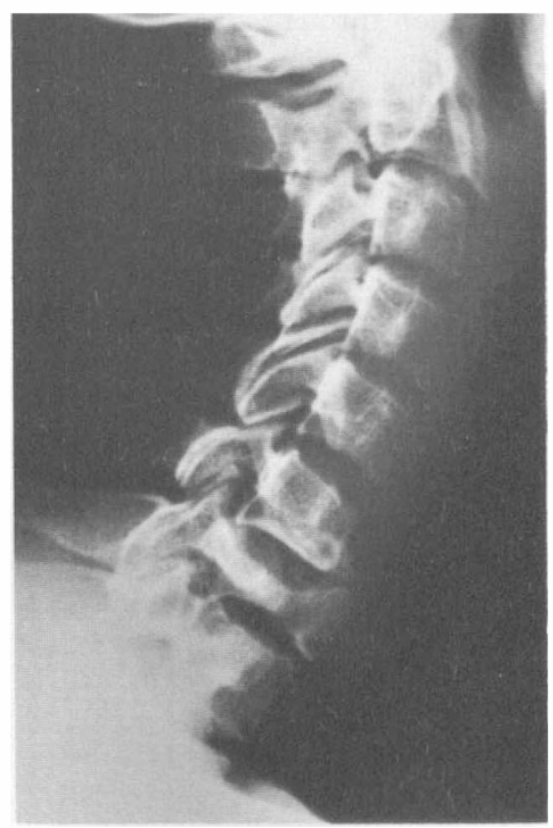

Figure 3 A lateral view of the cervical spine showing crush fracture of a vertebral body. 
Table II Degree of spinal cord injury

\begin{tabular}{|c|c|c|c|c|c|c|}
\hline \multirow{2}{*}{$\begin{array}{l}\text { Spinal cord } \\
\text { injuries } \\
\text { on admission }\end{array}$} & \multicolumn{2}{|c|}{ Compression } & \multicolumn{2}{|c|}{$\begin{array}{l}\text { Type of injury } \\
\text { Crush }\end{array}$} & \multirow{2}{*}{$\begin{array}{l}\text { Total } \\
\text { Number }\end{array}$} & \multirow[b]{2}{*}{$\%$} \\
\hline & Number & $\%$ & Number & $\%$ & & \\
\hline A & 48 & $8 \%$ & 255 & $70 \%$ & 303 & $31 \%$ \\
\hline B & 44 & $7 \%$ & 61 & $16 \cdot 5 \%$ & 105 & $11 \%$ \\
\hline C & 108 & $17 \%$ & 32 & $9 \%$ & 140 & $14 \%$ \\
\hline D & 159 & $26 \%$ & 16 & $4 \%$ & 175 & $18 \%$ \\
\hline E & 261 & $42 \%$ & 2 & $0.5 \%$ & 263 & $26 \%$ \\
\hline Total & 620 & $100 \%$ & 366 & $100 \%$ & 986 & $100 \%$ \\
\hline
\end{tabular}

Table II shows the type of fracture and degree of spinal cord damage on admission. The degree of spinal damage was assessed based on neurological and functional state of the patients (Frankel et al., 1969).

The compression fractures are rarely accompanied by complete spinal cord lesions (8\%). Minor neurological deficits and no neurological deficits (gorup E) were recorded in $159(26 \%)$ and $261(42 \%)$ of the compression fracture patients respectively. The explosion fracture group showed an entirely different distribution: complete spinal cord injuries made up $70 \%$ of cases, massive paresis (group B and C) involved $25 \cdot 5 \%$, and only 2 patients had no neurological disorder.

\section{Methods of treatment}

Table III presents the methods of treatment and the type of spinal fracture. Conservative treatment was applied more frequently (66\% of 986 cases) than surgical intervention. The conservative methods utilised corsets and orthopaedic collars most frequently (66\% of 647$)$. Surgical treatment consisted mainly in decompression and spinal fusion through an anterior approach (54\% of 339 cases) and spring alloplasty-in the lower segment of the spine. The method of treatment is to a large extent dependent upon the type of spinal injury. In typical compression fractures surgical intervention was carried out in only $14.8 \%$ of 620 patients; while in 'crush' fractures, surgery was performed in the majority of cases $(67 \cdot 5 \%$ of 366$)$.

In typical compression fractures surgery is only performed if the displacement of the fragmented intervertebral disc into the vertebral canal and compression of the spinal cord are demonstrated by CT scan or by contrast medium examination. In crush fractures, involving fragmentation of the vertebral body and displacement of the fragments into the vertebral canal (by over $20 \%$ ), operative treatment is usually decided upon, and consists of removal of the crushed body, decompression of the spinal cord and spinal fusion by bone plate grafting from an anterior approach (Kiwerski, 1982). The treatment is restricted to traction only, in cases of late admission (several days after injury) with symptoms of complete SCI. In such instances neurological recovery following spinal cord decompression is unlikely to be expected in complete cases, while spinal stability may be obtained by conservative methods.

\section{Results of treatment}

Table IV presents the results of treatment, juxtaposing the neurological state on admission and after treatment, taking into account the type of fracture and the 


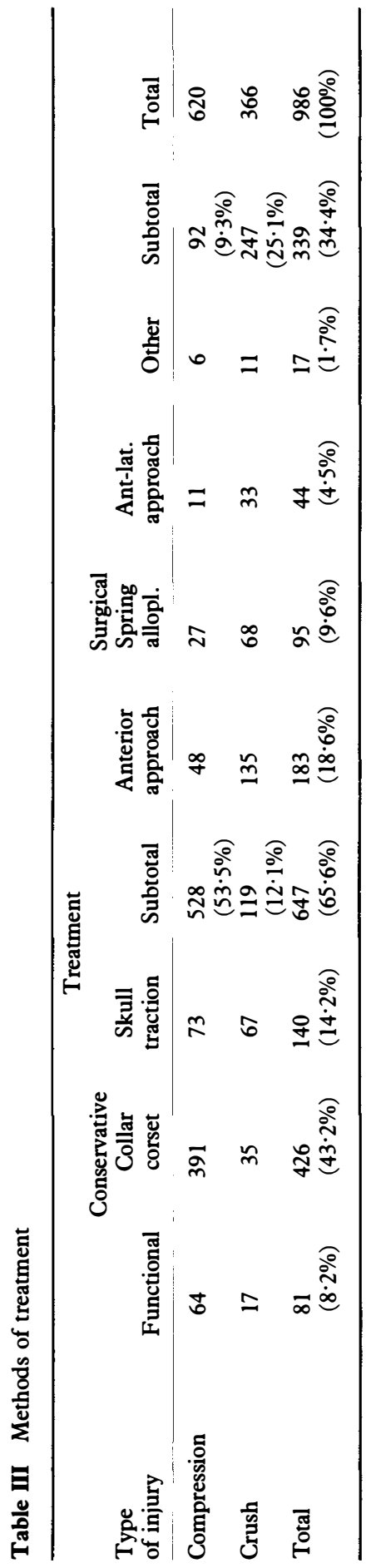


basic method of treatment. Neurological improvement (by at least one degree in the international scale) was obtained in $57 \%$ of 666 patients, while in $37 \%$ the neurological state was markedly better (withdrawal of neurological disorders or improvement by two or more degrees in Frankel's scale). The incidence and degree of the neurological improvement differed with relation to the type of fracture and the method of treatment. It is understandable that neurological and functional improvement is much easier to achieve in patients with typical compression fractures (Table V), which are, as a rule, accompanied by only incomplete damage to the spinal cord. Conservative treatment of patients with typical compression fractures lead to noticeable neurological improvement in $72 \%$ of 259 cases. Surgical treatment in this group of patients yielded improvement in $83 \%$ of 81 cases.

Definitely worse results of treatment were noted in patients with crushed vertebral body (Table VI). Only $17 \cdot 7 \%$ of 96 patients conservatively treated

Table IV Neurological improvement

\begin{tabular}{|c|c|c|c|c|c|}
\hline \multirow{2}{*}{$\begin{array}{l}\text { Neurological Status } \\
\text { before - af ter } \\
\text { treatment treatment }\end{array}$} & \multicolumn{4}{|c|}{ Type of injury } & \multirow[b]{2}{*}{ Total } \\
\hline & $\begin{array}{c}\text { Compre } \\
\text { Conservative }\end{array}$ & on & $\begin{array}{c}\text { Crus } \\
\text { Conservative }\end{array}$ & Surgical & \\
\hline \multicolumn{6}{|l|}{ (A) Changed } \\
\hline A-D & - & - & - & 7 & 7 \\
\hline $\mathrm{A}-\mathrm{C}$ & 3 & 1 & - & 5 & 9 \\
\hline A-B & - & 1 & 2 & 14 & 17 \\
\hline B-E & 3 & - & - & 2 & 5 \\
\hline B-D & 20 & 8 & 6 & 29 & 63 \\
\hline$B-C$ & 8 & 4 & 3 & 14 & 29 \\
\hline C-E & 13 & 4 & 1 & 8 & 26 \\
\hline C-D & 48 & 22 & 2 & 18 & 90 \\
\hline D-E & 92 & 27 & 3 & 12 & 134 \\
\hline \multirow{2}{*}{\multicolumn{6}{|c|}{ (B) Unchanged }} \\
\hline & & & & & \\
\hline A-A & 28 & 5 & 73 & 114 & 220 \\
\hline B-B & 1 & 1 & 3 & 3 & 8 \\
\hline $\mathrm{C}-\mathrm{C}$ & 14 & 3 & 2 & 2 & 21 \\
\hline D-D & 29 & 5 & 1 & 2 & 37 \\
\hline Sub-total & 72 & 14 & 79 & 121 & 286 \\
\hline (C) Total cases treated & 259 & 81 & 96 & 230 & 666 \\
\hline Norm-Norm & 255 & 6 & 1 & 1 & 263 \\
\hline \multirow{3}{*}{$\begin{array}{l}\text { Mortality in Complete } \\
\text { (D) Total }\end{array}$} & 10 & 2 & 20 & 18 & 50 \\
\hline & 6 & 1 & - & - & 7 \\
\hline & 530 & 90 & 117 & 249 & 986 \\
\hline
\end{tabular}

Table $\mathbf{V}$ Neurological improvement in patients with compression fractures

\begin{tabular}{|c|c|c|c|c|c|c|c|c|}
\hline \multirow{2}{*}{$\begin{array}{l}\text { Admission } \\
\text { A }\end{array}$} & \multirow{2}{*}{$\begin{array}{l}\text { A } \\
33\end{array}$} & \multirow{2}{*}{$\begin{array}{l}\text { B } \\
1\end{array}$} & \multirow{2}{*}{$\frac{C}{4}$} & \multirow{2}{*}{$\begin{array}{l}\text { D } \\
-\end{array}$} & \multirow{2}{*}{$\begin{array}{l}\mathrm{E} \\
-\end{array}$} & \multirow{2}{*}{$\begin{array}{r}\text { Total } \\
38\end{array}$} & \multicolumn{2}{|c|}{$\begin{array}{l}\text { Discharge } \\
\text { Improvement }\end{array}$} \\
\hline & & & & & & & 5 & $(13 \%)$ \\
\hline B & - & 2 & 12 & 28 & 3 & 45 & 43 & $(95 \%)$ \\
\hline C & - & - & 17 & 70 & 17 & 104 & 87 & $(83 \%)$ \\
\hline D & - & - & - & 34 & 119 & 153 & 119 & $(77 \%)$ \\
\hline \multirow[t]{2}{*}{$\mathrm{E}$} & - & - & - & - & - & 261 & 261 & \\
\hline & & & & & Total & 601 & & \\
\hline
\end{tabular}


Table VI Neurological improvement in patients with crush fractures

\begin{tabular}{lcrrrrrrr}
\hline Admission & A & B & C & D & E & Total & $\begin{array}{c}\text { Discharge } \\
\text { Improvement }\end{array}$ \\
\hline A & 187 & 16 & 5 & 7 & - & 215 & 28 & $(13 \%)$ \\
B & - & 6 & 17 & 35 & 2 & 60 & 54 & $(90 \%)$ \\
C & - & - & 4 & 20 & 9 & 33 & 29 & $(87 \%)$ \\
D & - & - & - & 3 & 15 & 18 & 15 & $(83 \%)$ \\
E & - & - & - & - & 2 & 2 & & \\
\end{tabular}

showed improvement. The results of surgical treatment were better, but still not nearly as good as those obtained in compression fractures. Improvement was recorded in $48 \%$ of 230 cases. The mortality rate amounted to $6 \%$ in this group, differing with relation to the type of fracture and the degree of spinal cord lesion. In compression fractures the mortality was $3 \%$ of 620 , in crush fractures it exceeded $10 \%$ of 366 cases. In partial spinal cord injuries (SCI) the mortality rate was slightly over $1 \%$ of 683 patients whereas in those with complete injuries it amounted to $16 \%$ of 303 patients.

The difference between the results of treatment of SCI in typical compression and crush fractures is due mainly to the fact that damage to the spinal cord is, as a rule, much more severe in crush than it is in compression fractures. Tables $\mathrm{V}$ and VI show that in injuries involving the same degree of damage to the spinal cord, basically the same neurological recovery is obtained in patients in both groups of fractures.

\section{Discussion}

The presented data point out the significant differences between the two kinds of spinal injuries which are frequently referred to as 'compression fractures'. Typical compression fractures are more frequent in the middle-aged and the elderly, being rarely accompanied by massive or complete SCI, and most frequently without significant neurological disorder. Hence, the indications for surgical treatment of these fractures are infrequent, and the results of treatment are, as a rule, good. The mortality rate in this group of patients is not high, despite a greater number of elderly patients.

In patients with explosion fractures, the situation is entirely different. Such injuries mainly occur in young people following a serious spinal injury. Portions of fragmented vertebral body often damage the spinal cord or lead to secondary spinal cord necrosis as a consequence of massive compression of the spinal cord and vessels, giving symptoms of either complete or severe spinal cord lesion. Under such circumstances early surgical decompression is frequently indicated. In cervical spinal injuries it is frequently advisable to remove a part or the whole of the crushed vertebral body, while at lower levels the spinal cord should be decompressed through an antero-lateral approach (Riska, 1976), and the injured spinal segment should be stabilised either by Harrington method (Dickson et al., 1978; Svenson et al., 1984), spring alloplasty together with bone grafting (Weiss 
and Kiwerski, 1980) or by some other stabilisation method (Jacobs et al., 1982; Stauffer, 1984; Tkaczenko, 1974).

The presented data appear to be sufficient to justify the necessity of considering these two kinds of spinal damage separately instead of grouping them together as 'fractures through a compression mechanism'.

\section{Conclusions}

Typical compression fractures differ significantly from explosion fractures with regard to their incidence, the age of patients, neurological changes, the indications for surgery and the results of treatment. On account of the differences, these two kinds of spinal injuries should be considered separately with regard to the mechanism of injury, prognosis and the assessment of the results of treatment.

\section{References}

BEDBROOK GM 1971 Stability of spinal fractures and fracture dislocations. Paraplegia 9:23-32.

BUHR AJ 1966 The aging spine, fractures and osteoporosis. Nova Scotica Medical Bulletin 45:317-321.

Decoulx P 1981 Injuries to the cervical spine between $\mathrm{C}_{2}$ and $\mathrm{C}_{7}$ without medullary lesions. Revue de Chirurgie Orthopedique 67:395-405.

DENIS F 1983 The three-column spine and its significance in the classification of acute thoracolumbar spine injuries. Spine 8:817-826.

DICKSON JH, HARRINGTON PR, ERWIN WD 1978 Results of reduction and stabilisation of the severely fractured thoracic and lumbar spine. Fournal of Bone and Foint Surgery 60-A:799-807.

FRANKEL HL et al. 1969 The value of postural reduction in the initial management of closed injuries of the spine. Paraplegia 7:179-192.

HoLDSWORTH F 1970 Fractures, dislocations and fracture-dislocations of the spine. Fournal of Bone and foint Surgery 52:1534-1551.

JACOBS RR, ASHER MA, SNIDER RK 1982 Thoracolumbar spinal injuries. A comparative study of recumbent and operative treatment in 100 patients. Spine 5:463-477.

KIWERSKI J 1982 Anterior interbody fusion in treatment of cervical spine trauma. International Orthopaedics 6:255-258.

KIWERSKI J, KULIKOWSKI J 1986 Influence of spine injury mechanism on the degree of damage of nerve elements contained in spinal canal. Chirurgia Narzadaw Ruchu I Ortopedia Polska 51:4-9(Engl. abstr.)

MCAFEE P C1982 The unstable burst fracture. Spine:365-373.

RISKA E 1976 Antero-lateral decompression as a treatment of paraplegia following vertebral fracture in the thoraco-lumbar spine. Reconstruction Surgery and Traumatology 15:17-35.

STAUFFER SHE 1984 Internal fixation of fractures of the thoraco-lumbar spine. Fournal of Bone and foint Surgery 66-A:1136-1138.

SVENSON D, AARO S, OHLEN G 1984 Harrington instrumentation for thoracic and lumbar vertebral fractures. Acta Orthopaedica Scandinavica 55:38-47.

TKACZENKO SS 1974 New method of fixation and posterior spondylodesis in the treatment of compression fractures of the spine. Ortopediia Traumatologiia I Protezirovanie 11:22-27.

WEISS M, KIWERSKI J 1980 Federalloplastik bei der Behandlung von Frakturen der Wirbelsäule mit Rückenmarkverletzung. Beitrage zur Orthopandie und Traumatologie 27:246-252. 